\title{
WAGNER, Ulrich, ZIEGLER, Walter, Lorenz Fries. Chronik der Bischöfe von Würzburg 742-1495, t. 6 : Die Miniaturen der Bischofschronik
}

\section{Pierre Monnet}

\section{(2) OpenEdition \\ Journals}

Édition électronique

URL : http://journals.openedition.org/ifha/1468

DOI : $10.4000 /$ ifha. 1468

ISSN : 2198-8943

\section{Éditeur}

IFRA - Institut franco-allemand (sciences historiques et sociales)

\section{Référence électronique}

Pierre Monnet, « WAGNER, Ulrich, ZIEGLER, Walter, Lorenz Fries. Chronik der Bischöfe von Würzburg 742-7495, t. 6: Die Miniaturen der Bischofschronik», Revue de l'IFHA [En ligne], Date de recension, mis en ligne le 01 janvier 1998, consulté le 22 septembre 2020. URL : http://journals.openedition.org/ifha/ 1468 ; DOI : https://doi.org/10.4000/ifha.1468

Ce document a été généré automatiquement le 22 septembre 2020.

(C)IFHA 


\title{
WAGNER, Ulrich, ZIEGLER, Walter, Lorenz Fries. Chronik der Bischöfe von Würzburg 742-1495, t. 6 : Die Miniaturen der Bischofschronik
}

\author{
Pierre Monnet
}

1 Cette reproduction commentée des 176 miniatures illustrant la célèbre "Chronique des évêques de Wurtzbourg« constitue en fait le sixième tome d'une édition complète de ce texte rédigé par le secrétaire et bibliothécaire du Conseil de Wurtzbourg Lorenz Fries (1489-1550) chargé de mettre en forme l'histoire de l'évêché et de la ville depuis la christianisation de la Franconie jusqu'à la mort de l'évêque Rudolf von Scherenberg en 1495. Les cinq premiers volumes (dont deux parus à ce jour) regroupent quant à eux le texte même de la chronique.

2 Cette édition est précieuse à plus d'un titre. Tout d'abord elle s'appuie sur le seul exemplaire de la chronique conservé aux archives de Wurtzbourg (un manuscrit de 708 pages), lequel constitue un des trois exemplaires autorisés par le chapitre cathédral en 1547. Il s'agit donc d'un texte rare et d'une version officielle, contrôlée. En second lieu, nous avons là un ouvrage dont le contenu d'une part reflète une forme typique d'historiographie mi-cléricale mi-bourgeoise de l'Allemagne du Sud entre Moyen Age tardif et Réforme, mais dont l'illustration d'autre part, réalisée par le peintre wurtzbourgeois Martin Seger (1515/1520-1581) entre 1572 et 1574, traduit un renouvellement complet de la thématique historique et de l'approche du passé. Les rapports entre texte et image montrent ainsi qu'il n'y a pas qu'une génération de décalage entre le chroniqueur et le peintre. En effet, non seulement les miniatures de Martin Seger traduisent l'influence de l'école allemande incarnée tant par Dürer et Cranach que par Grien, Holbein et Altdorfer, un art encore partagé entre gothique tardif et renouveau, mais elles les dépassent aussi à l'occasion de cette commande en donnant au texte de Lorenz Fries une cohérence iconographique chargée de souligner le message politique. De la sorte, ce que la synthèse nécessairement composite du 
chroniqueur ne pouvait pas réaliser (il fallait rassembler plus de sept siècles d'histoire mêlant les destins impériaux, princiers, épiscopaux et urbains...), le trait de Martin Seger a pu bien mieux l'atteindre. C'est ainsi qu'on voit mises en valeur l'autorité et la politique territoriale du prince-évêque sans pour autant que les débats religieux du temps soient passés sous silence. De même perçoit-on mieux par l'image le transfert des attributs de la souveraineté royale aux princes de l'Empire, processus tout à fait achevé dans les années 1570. Très instructives sont en ce sens les illustrations insistant sur l'exercice collégial du droit et de la jurisprudence dont le XVIe s. marque, quoi qu'on en dise, le triomphe. Tout aussi révélatrice est la place qu'occupe surtout dans les scènes de haute époque (chronique de Lorenz Fries pour les Xe-XIe-XIIe ss.) les détails et représentations de nature économique: vins, marchés et transports de produits correspondant au profil des échanges dans l'espace franconien aux XVe et XVIe ss. Il n'est pas jusqu'aux reproductions nombreuses d'armes et de scènes de bataille qui ne traduisent la place centrale qu'occupe la guerre dans la société allemande du siècle des Réformes. Le pinceau de Martin Seger a donc su se faire assez réaliste et atténue ce faisant le souffle épique de la chronique pour une part encore très médiévale de Lorenz Fries: c'en était bien définitivement fini dans les années 1570 d'une vision du monde qui combinait noirceur, fraîcheur et naïveté. 